\title{
Role-plays for preparing physics teaching assistants and learning assistants
}

\author{
Monica K. Cook, and Joshua S. Von Korff \\ Georgia State University, Department of Physics and Astronomy, 25 Park Place, Atlanta, GA 30303
}

\begin{abstract}
Preparing graduate teaching assistants (TAs) and undergraduate learning assistants (LAs) to teach in physics classrooms is a topic of great interest in physics education research. We investigate the use of role-play performances to prepare TAs and LAs to teach students in introductory physics tutorials, labs, and SCALE-UP classes. Each role-play addressed specific pedagogical knowledge and specific disciplinary content. We find that our role-plays helped TAs and LAs to express their ideas about discursive teaching methods and fostered productive discussions about teaching physics.
\end{abstract}

\section{INTRODUCTION}

As graduate teaching assistants (TAs) and undergraduate learning assistants (LAs) become increasingly essential to undergraduate physics instruction, researchers in physics education and other science education disciplines have developed important insights into their preparation and professional development [1-6]. Here, we discuss the implementation of role-plays to prepare physics TAs and LAs. We argue that the role-play performances activated the participants' teaching resources, or their intuitive ideas about teaching that come from participants' past experiences.

Physics education researchers have modeled student learning using resources [7, 8]. According to the resource model, students have resources and teachers help students by "activating" a set of productive resources that leads to a correct conceptual understanding. Researchers have also applied the resource model to training physics TAs by examining their resources and beliefs [9-11]. The TA and LA resources about teaching described in this paper are similar in nature to TA resources that have been identified by previous research. However, the previous teaching resources were detected by analyzing interviews and classroom teaching of participants, while the teaching resources in this paper were detected by analyzing class discussions and role-play activities.

Role-plays provide a framework to practice guiding students before TAs and LAs are in the classroom with real students. A previously-identified TA belief is that "guiding students is less certain than telling them (the right answer)" because it introduces unnecessary uncertainty into the learning process [12]. Researchers have established that instructors who practice guiding students have less negative attitudes toward instructional reform and increased buy-in to inquirybased learning (IBL) [1]. Our role-play activities also give TAs and LAs a chance to think about what they would say to a student who is having a particular conceptual difficulty, and to discuss their thinking with other TAs and LAs.

Role-playing occurs when participants act out a fictitious dialogue that they have invented. It is not expected or desirable that participants will write down the dialogue that they will perform. Instead, role-plays should have some degree of spontaneity [13]. Role-plays and another performance activity, known as micro-teaching, have been used in the professional development of teacher candidates. In micro-teaching, teacher candidates teach short lessons to a group of supervisors, peers, or students, who give immediate feedback to the candidate [14]. Role-plays and micro-teaching are similar in that students or teacher candidates must make decisions to plan how they will perform the activity. In micro-teaching, the audience is genuinely unfamiliar with the physics learning activity, and the situations that the teacher prepared for may not arise in student discussion [13]. On the other hand, the audience in our role-plays has seen the physics activity in advance and practiced thinking like introductory-level students with assistance from a pre-role-play homework set.

Education researchers in various science disciplines have investigated using role-plays to teach content and skills to students [15-18]. Several researchers have used role-plays to prepare pre-service science teachers [18-20]. In an instance described in Palmer (2006), pre-service science teachers took on the roles of students, while the professor in their professional development class modeled expert science teaching [20]. In physics education research (PER), a performance activity called Energy Theater has been used in a professional development course for in-service physics teachers [21]. Energy Theater has teachers perform the roles of various types of energy and work together to figure out how to make their performances reflect their conceptual understanding of energy [22].

\section{DESIGN AND METHODS}

\section{A. Background}

Our role-plays each have a teaching focus (e.g. "asking questions") and a content focus (e.g. Newton's second law). Participants must think about how to teach specific physics content in different scenarios. The role-plays consist of four stages: preparation, planning, performance, and postdiscussion. The preparation stage includes homework related to the teaching and content focuses that participants prepare before class, and pre-discussions during class that further prepare participants. During the in-class pre-discussion, the roleplay facilitator (second author JSV) asked participants a set of questions about the teaching topic: (1) about the advice they would give to instructors, (2) any challenges that might occur, and (3) any situations from their teaching that relate to 
the teaching topic. During the planning stage, participants divided into groups to discuss their role-play prompts, which included physics questions and brief descriptions of each role. One participant per group played the role of a TA and the rest played the roles of introductory physics students. The participants decided who would play each role, discussed how to play the roles, and practiced their performances. Next, each group presented their role-play performance. The facilitator then led the class in a post-performance discussion, asking the same questions that he asked during the pre-performance discussion. All physics questions used in the role-plays come from the Open Source Tutorials (OST) [23].

\section{B. Participants}

The TAs under consideration taught in one of the three types of introductory physics labs at Georgia State University (GSU): traditional, inquiry-based, and SCALE-UP (studio). The LAs taught using Tutorials in Introductory Physics [24] for an hour before the inquiry-based labs and met once a week to prepare for upcoming tutorials. All TAs and LAs at GSU must take a physics pedagogy course called Teaching Physics in which they read and discuss papers on physics pedagogy, write reflections on their readings and their teaching, and receive feedback on their classroom teaching. During Spring 2016, the TAs and LAs in Teaching Physics participated in the role-plays described in this paper. The TAs and LAs who participated in this research are collectively referred to as participants, and are identified by code names to ensure anonymity.

\section{Analysis}

Using constant comparison [25], we analyzed video data and field notes to examine the statements and actions of four LAs and ten TAs who participated. The video data was first transcribed and coded using open coding to search for interesting features. Then proto-categories were generated, such as "resources held by participants." The second phase was selective coding, in which we searched the transcripts for additional statements that would match the categories created in the first phase. Finally, we used axial coding to generate our final categories, such as "resources about student motivation" and "resources about the role of the TA." While we found other categories of resources activated by the role-plays, the categories named in the previous sentence are the focus of this paper.

\section{TEACHING RESOURCES ACTIVATED BY THE ROLE-PLAYS}

To investigate how teaching resources were activated by the role-play performances, we compared the pre-discussion responses of participants to the post-discussion responses of participants, as described in Section II A of this paper. We found that participants expressed ideas after the role-play performances that they did not express before the performances, indicating that the role-plays activated participants' teaching resources. The pre-discussion occurred before the roleplay performance, while the post-discussion occurred after the role-play performance. Typically, participants would express about four unique ideas before the performance, while participants would express about six ideas during the postdiscussion, some of which were not in the pre-discussion. The participants' responses indicate that the role-plays caused them to recall experiences from their own teaching and to find connections to the role-play scenarios. Here, we show a link between four resources expressed by participants during the post-discussions and the same participants' role-play performances. Note that not all participants held the same resources about teaching; a role-play performance might activate a teaching resource held by one or two participants but not by others.

\section{A. Resources about student motivation}

The two resources about student motivation that are discussed in this paper come from the role-play about "participation." The pre-discussion questions for the "participation" role-play were posited to the whole class before the role-play performances. The questions were: (1) What advice would you give to instructors about encouraging student participation? (2) What challenges related to participation might come up while teaching? (3) What situations from your teaching related to participation can you recall? The same questions were asked during the post-discussion after the role-play performances.

\section{Students are motivated by graded participation points.}

The resource that students are motivated by graded participation points came up during the role-play on "participation." No participants expressed the resource during the prediscussion. However, the resource came up during the postdiscussion by one participant whom we call Eugene here. (The same questions were asked during the post-discussion after the role-play performances as were asked during the prediscussion.) During the post-discussion, Eugene answered question (1) as follows:

Eugene: Yeah, just don't be afraid to mention the fact that they are getting graded because sometimes that's necessary to get them to follow your instructions.

One can trace the activation of this resource to Eugene's role-play performance, during which he played the role of a student [S2] who encouraged another student [S1], played by Luis, to stop cheating and participate in group work. 
[S1] Luis: What is the answer?

[S2] Eugene: Oh no, I don't want to show you what the answer is. You have to participate with us. We'll get points taken off if you don't. So do you understand what this velocity graph is?

[S1] Luis: Yes, I understood. Is this the answer to question number one?

\section{(Role-play performance)}

Eugene also responded to question (3) during the postdiscussion by describing an incident from his teaching.

Eugene: In my last class I had a student on his phone. I [mentioned] that he was being graded on his participation and I would have to knock off points. And he just really kind of opened up and said, "I just really don't know where to start." And I was able to help him from that point.

The above quote suggests that encountering a similar situation in the role-play made Eugene recall his previous teaching experiences and connect it to the role-plays.

\section{Students are deterred from participating by closed questions.}

Another teaching resource activated by the role-plays was that students are deterred from participating by closed questions. During the role-play on "participation," no participants expressed this resource during the pre-discussion, but one participant, Karla, expressed this resource in the postdiscussion. Karla said the following in the post-discussion in response to question (1).

Karla: I would say don't ask closed-ended questions so like yes or no questions like "Do you understand?" or "Do you agree?" Ask for explanations and reasoning and things like that. I think an answer in a single word, you should probably rephrase your question.

What Karla expresses above is a belief that students find "closed-ended" questions discouraging to participation. Thus, she advises other participants not to ask closed questions while teaching if they want to encourage student participation.

During her groups' role-play performance between the preand post-discussions, Karla played the role of a student who was playing games on her phone instead of participating in the group assignment.

[TA] Boris: Alright so, Karla?

[S1] Karla: What?

[TA] Boris: What's the derivative of position?

[S2] Ronald: Acceleration.

[S1] Karla: Yeah, acceleration.

(Role-play performance)

One can see a connection from Karla's role-play performance to the activation of the resource that Karla later expressed in the post-discussion. The TA in Karla's group, played by Boris, attempted to get Karla [S1] and Ronald [S2] to participate. In the role-play performance, Boris asked Karla and Ronald a series of closed questions, to which they responded with short, one-word answers. Thus Karla in the role of a student responds to a TA who asks closed questions with only minimal participation.

\section{B. Resources about the role of the TA}

The two resources about the role of the TA that are discussed in this paper occurred during the role-play about "asking questions". During this role-play, the facilitator asked the following questions to the class during both the pre- and postdiscussions before and after the role-play performances: (1) What advice would you give to instructors about asking students questions? (2) What challenges related to asking questions might come up while teaching? (3) What situations from your teaching related to asking questions can you recall?

\section{The TA's role is to facilitate students working together.}

During the post-discussion after the role-play performance, a participant named Milton expressed the resource that the TA's job is to facilitate students working together. This resource was not expressed during the pre-discussion before the role-plays by any participants. In response to question (1) during the post-discussion, Milton says the following

Milton: Because [the] TA is like a leader, he or she should explain less compared to [asking] question[s]. Students should teach to each other, not [have the] TA teach them.

In Milton's view, the TA is tasked with eliciting student ideas through questions about student reasoning. Milton describes TAs as leaders whose job is to assist students in teaching each other.

The activation of Milton's resource has a connection to his role-play performance, during which he played the role of the TA. During his group's performance, Milton had the participants who played students explain their ideas to each other and work together. Several times during the group's performance, Milton asked those in student roles to respond to other students' ideas, asked them many open questions, and offered a few direct explanations.

\section{TAs should explain concepts to students who reach a "wall."}

During the post-discussion, participants including Milton and Francisco expressed the resource that TAs should explain concepts to students when they reach a "wall." This resource was not expressed during the pre-discussion before the roleplays. 
Milton responded to post-discussion question (3) as follows:

\begin{abstract}
Milton: If a student hasn't any idea about the fundamental concept, it's a catastrophe for me. For example, if they can't remember the second law of the Newton - or third law - you should explain it again for them.
\end{abstract}

In the above quote, Milton expressed apprehension around the idea of a student that does not have the proper background knowledge to answer a question. This "wall," called a "knowledge wall," a "discussion wall," and a "vocabulary wall" by various participants during the discussion, stems from a lack of student background knowledge. Many participants brought up the idea of a "wall" beyond which students need to be given a direct explanation by a TA as opposed to the TA continuing to ask questions.

Francisco also expressed agreement with this resource. Francisco's response to post-discussion question (3) is as follows:

Francisco: I'm going to start taking the first five to ten minutes and explain just what they need to know for [the lab] ... Because they need to have that, it's both like a knowledge wall and a discussion wall.
This resource has a link to the role-play performances. Two of the groups performed the roles of students who were lacking background knowledge necessary to solve the physics problem in the scenario. The participants who played the TAs in these scenarios asked questions until they got to the point where they hit the students' wall, or the point where they reached the end of their background knowledge.

\section{CONCLUSIONS}

The activation of participants' teaching resources by the role-plays allowed participants to discuss and examine their thinking and the thinking of others. The role-plays also provided an opportunity for participants to prepare for real teaching scenarios by practicing outside of their real classrooms.

Future work is needed to determine to what extent the roleplays affect how participants teach in their classrooms, and if participants' resources about teaching physics changed over time in response to the role-plays.

\section{ACKNOWLEDGMENTS}

We would like to thank Laura Kiepura for her help with this work and the TAs and LAs who participated. This work was funded by the National Science Foundation (Grant No. DUE 1347510) and by the Center for Excellence in Teaching and Learning at Georgia State University.
[1] K. Bohrer, B. D. Stegenga, and A. Ferrier, in Proc. 28th Work. Assoc. Biol. Lab. Educ. (2007), pp. 335-346.

[2] T. Pentecost et al., J. Coll. Sci. Teach. 41, 6 (2012)

[3] C. Singh, AIP Conf. Proc. 1179, 59 (2009).

[4] J. A. Gilreath and T. F. Slater, Phys. Educ. 29, 200 (1999).

[5] E. Etkina, J. Grad. Teach. Assist. Dev. 7, 123 (2000).

[6] G. L. Cochran, L. Wells, and D. T. Brookes, 2013 Phys. Educ. Res. Conf. Proc. 97 (2013).

[7] D. Hammer, Am. J. Phys. 68, S52 (2000).

[8] D. Hammer and A. Elby, J. Learn. Sci. 12, 53 (2003).

[9] R. M. Goertzen, R. E. Scherr, and A. Elby, Phys. Rev. ST Phys. Educ. Res. 6, 10105 (2010)

[10] R. M. Goertzen, R. E. Scherr, and A. Elby, Phys. Rev. ST Phys. Educ. Res. 6, 20125 (2010).

[11] R. M. Goertzen, R. E. Scherr, and A. Elby, Phys. Rev. ST Phys. Educ. Res. 5, 20109 (2009).

[12] D. B. Harlow et al., J. Res. Sci. Teach. 50, 1098 (2013)

[13] S. Sharan and Y. Sharan, Small-Group Teaching (Educational Technology Publications, Englewood Cliffs, N.J., 1975).

[14] D. Allen, Micro-Teaching: A Description (Stanford University,
1967).

[15] P. T. Jackson and J. P. Walters, J. Chem. Educ. 77, 1019 (2000)

[16] A. M. Fox and L. L. Loope, J. Nat. Resour. Life Sci. Educ. 36, 147 (2007)

[17] M. Smythe and D. Higgins, J. Chem. Educ. 84, 241 (2007)

[18] E. V Howes and B. C. Cruz, J. Elem. Sci. Educ. 21, 33 (2009)

[19] D. Metz, Teach. Educ. 16, 165 (2005)

[20] D. H. Palmer, Res. Sci. Educ. 36, 337 (2006)

[21] H. G. Close and R. E. Scherr, Int. J. Sci. Educ. 37, 1 (2015)

[22] R. E. Scherr, H. G. Close, E. W. Close, V. J. Flood, S. B. McKagan, A. D. Robertson, L. Seeley, M. C. Wittmann, and S. Vokos, Phys. Rev. ST Phys. Educ. Res. 9, 20105 (2013)

[23] A. Elby et al., Open Source Tutorials in Physics Sensemaking, Suite I (2010).

[24] L. C. McDermott and P. S. Shaffer, Tutorials in Introductory Physics (Pearson Education, 2001).

[25] K. Charmaz and J. A. Smith, in Qual. Psychol. A Pract. Guid. to Res. Methods, edited by J. A. Smith (Sage, 2003), pp. 81110. 